\title{
Peptidoglycan synthesis in Salmonella typhimurium 2616
}

\author{
David Gally $\dagger$ and StePhen CoOPER* \\ Department of Microbiology and Immunology, University of Michigan Medical School, Ann Arbor, \\ Michigan 48109-0620, USA
}

(Received 20 July 1992; revised 9 December 1992; accepted 16 February 1993)

\begin{abstract}
HPLC analysis of peptidoglycan synthesis in Salmonella typhimurium strain 2616 has revealed that: (i) there is observable variation in the composition, but no significant variation in the overall degree of cross-linking, of newly synthesized peptidoglycan during the division cycle; (ii) the types of muropeptide that constitute peptidoglycan do not vary over a wide range of growth rates; and (iii) the composition and maturation kinetics of $S$. typhimurium peptidoglycan are, as expected, similar to those of Escherichia coli. We propose a unitary model of peptidoglycan synthesis, with single-strand incorporation occurring at both side wall and polar sites.
\end{abstract}

\section{Introduction}

In order to understand the mechanisms involved in septation/constriction of Gram-negative, rod-shaped bacteria, several studies have focused on whether a structural difference exists between peptidoglycan synthesized during constriction and that synthesized during elongation of the cylindrical wall. Differences in structure would support the view of septal synthesis in which predominantly independent or specific enzyme activities are involved in septum formation rather than side-wall growth. The most recent study of this kind analysed peptidoglycan synthesized in filamentous mutants undergoing resumption of constriction. Romeis et al. (1991) found only slight differences between peptidoglycan synthesized when constriction was minimal and when constriction was allowed to occur. De Jonge et al. (1989) obtained cells by centrifugal elutriation, and found compositional differences between peptidoglycan synthesized in predominantly constricting bacteria and that made in primarily elongating bacteria. However, the overall degree of cross-linking of peptidoglycan made at the two loci remained fairly constant. The interpretation of corrections applied to their results are still the subject of debate (Cooper, 1990, 1991 b; Driehuis et al., 1992).

An experimental analysis of wall growth during the

*Author for correspondence. Tel. (313) 764 4215; fax (313) 764 3562; e-mail Stephen_Cooper@um.cc.umich.edu.

$\dagger$ Present address: Department of Microbiology and Immunology, Bowman Gray Medical School, Winston-Salem, NC 27157-1064, USA.

Abbreviation: DAP, diaminopimelic acid. division cycle is best accomplished with unperturbed cells, pulse-labelled to reflect peptidoglycan synthesis over short periods. An analysis of the perturbation problem has been presented in detail (Cooper, 1991 $a$ ). The use of antibiotics (Romeis et al., 1991) may lead to perturbations which affect normal peptidoglycan synthesis. The use of centrifugal elutriation to obtain a synchronized culture, as used by De Jonge et al. (1989), has both practical and theoretical problems. A theoretical critique of the elutriation method has been presented (Cooper, 1991a).

The purpose of this publication is to clarify our current knowledge of compositional differences and similarities between peptidoglycan synthesized at polar sites as opposed to cylindrical sites. To this end, we have focused our study on Salmonella typhimurium 2616, which exhibits rapid and efficient uptake of the peptidoglycan-specific label diaminopimelic acid (DAP). The advantages of this strain over $E$. coli have been discussed in detail elsewhere (Cooper \& Metzger, 1986; Cooper et al., 1992). In addition, we have used membrane-elution to obtain newborn bacteria for analysis. Results obtained using the membrane-elution method have led to our understanding of the pattern of DNA replication during the bacterial division cycle (Cooper, 1991a). Membrane-elution studies with S. typhimurium 2616 and $E$. coli NC3 have also shown that there is a reproducible non-exponential pattern of peptidoglycan synthesis during the division cycle (Cooper, 1988; Cooper \& Hsieh, 1988). Theoretical considerations prompted by these findings suggest that the point at which septal peptidoglycan synthesis is greatest may not be at the end of the division cycle. One may divide the 
division cycle into two parts; the initial portion with a constant ratio of wall to mass synthesis, and the final portion with an elevated rate of wall to mass synthesis. The peak of the DAP to leucine incorporation ratio defines the time of maximum DAP incorporation into polar wall. Compositional differences between side and polar wall may occur during this time rather than at the extreme end of the division cycle, usually defined as that time in which constriction is most prominent in the culture.

The measurements of the relative rate of peptidoglycan during the division cycle were obtained using the backwards method of division-cycle analysis, i.e. the radiolabelling of an exponential culture followed by fractionation of cell ages by elution from a nitrocellulose membrane (Cooper, 1988; Cooper \& Hsieh, 1988, Gally et al., 1993). Maturational changes exhibited by pulselabelled peptidoglycan restrict the utility of the backwards method for the analysis of the composition of peptidoglycan synthesized at different times during the division cycle. This is because growth on the membrane subsequent to labelling and prior to elution will obscure the initial composition of peptidoglycan synthesized at different times during the division cycle. Consequently, the present study uses the forward method of analysis, i.e. the collection of newborn bacteria from a membrane followed by their subsequent labelling at different times. However, we do point out that the forwards method does not, from theoretical considerations as well as practical considerations, have the same degree of resolution provided by the backwards technique. For a complete discussion of this important distinction, see Cooper (1991a).

We have now analysed the composition of newly synthesized peptidoglycan from S. typhimurium 2616 using reverse-phase HPLC and find that the composition and maturation kinetics are similar to those shown for $E$. coli (Glauner \& Höltje, 1990). Interestingly, the degree of cross-linking increased with decreasing growth rate. We find no evidence for any systematic or significant variation in cross-linking during the division cycle. These results are consistent with a unitary, make-before-break, single-stranded, intercalation model for peptidoglycan assembly.

\section{Methods}

Bacteria and growth conditions. Salmonella typhimurium 2616 (lysA) (from Dr K. E. Sanderson, University of Calgary) was grown in C medium supplemented with $50 \mu \mathrm{g}$ lysine $\mathrm{ml}^{-1}$ (Cooper, 1988). Carbon sources (glucose, glycerol, succinate or acetate) were added to a final concentration of $0 \cdot 4 \%$. Penassay broth (Difco) was used for growth in undefined medium. Cells were grown at $37^{\circ} \mathrm{C}$ with rotary shaking.

Radioactive compounds. Tritium-labelled DAP (meso-2,6-diamino [3,4,5- $\left.{ }^{3} \mathrm{H}\right]$ pimelic acid; $\left.23 \mathrm{Ci} \mathrm{mmol}\right)$ was obtained from Research
Products International. Tritium-labelled $N$-acetylglucosamine $(N$ acetyl $\left[1,6{ }^{3} \mathrm{H}\right]$ glucosamine, $30 \mathrm{Ci} \mathrm{mmol}^{-1}$ ) and ${ }^{14} \mathrm{C}$-labelled leucine $\left(\left[1-{ }^{14} \mathrm{C}\right]\right.$ leucine; $\left.55 \mathrm{Ci} \mathrm{mmol}^{-1}\right)$ were obtained from American Radiolabeled Chemicals ( $1 \mathrm{Ci}=37 \mathrm{GBq}$.)

Analysis of composition of peptidoglycan synthesized during the division cycle with a 'forward' membrane-elution method. The backwards method for cell-cycle analysis (i.e. pre-labelling followed by separation of cells labelled at different ages by membrane-elution) is not applicable when there is maturation and/or turnover-reutilization of the material under investigation. Both of these conditions appear to occur during peptidoglycan synthesis (De Pedro \& Schwarz, 1981; Goodell \& Schwarz, 1983, 1985; Goodell, 1985; Cooper et al., 1992; Glauner \& Höltje, 1990). Therefore, we have analysed peptidoglycan synthesis at different times during the division cycle by the more conventional 'forward' synchronization approach.

S. typhimurium was grown in C medium (glycerol) to a concentration of $1 \times 10^{8} \mathrm{ml}^{-1}$, and $100 \mathrm{ml}$ was filtered through a membrane-elution apparatus. The number of cells eluting from the membrane was monitored to ensure that a normal elution curve was obtained. After $50-100 \mathrm{~min}$ of elution, samples of newborn cells were collected at $7 \mathrm{~min}$ intervals, placed into pre-warmed culture tubes, and incubation was continued at $37^{\circ} \mathrm{C}$. After $77 \mathrm{~min}$ of collection (equivalent to 1.2 generations), each tube contained cells of different cell-cycle ages. The last tube collected contained cells between 0 and $7 \mathrm{~min}$ after separation (i.e. newborn cells). The first tube collected contained cells that had grown for 70-77 min after release from the membrane; these cells had completed at least one round of division. Between the first and last tubes, the remaining tubes contained cells of different cell-cycle ages. The cells were labelled with $\left.{ }^{3} \mathrm{H}\right] \mathrm{DAP}\left(0 \cdot 2 \mathrm{nmol} \mathrm{m}^{-1}, 4 \cdot 4 \mu \mathrm{Ci} \mathrm{ml}^{-1}\right)$ for $7 \mathrm{~min}$. The cell concentration for each sample was determined at collection and at the time of radiolabelling; the ratio of these cell concentrations reveals the synchronous growth of cells during the division cycle. To confirm synchronous growth, the cell-size distribution, as well as the cell number, was monitored for each sample at the time of radiolabelling. After labelling, the tubes were transferred to a boiling water bath and hot $\operatorname{SDS}\left(90^{\circ} \mathrm{C}\right)$ added to a final concentration of $4 \%(\mathrm{w} / \mathrm{v})$. Approximately $10 \mathrm{mg}$ (dry weight) of carrier cells was added to each sample and the peptidoglycan from each tube was prepared for HPLC analysis.

Maturation of peptidoglycan. Bacteria growing exponentially for over 10 generations were labelled for either 0.5 or 2 min with tritiated DAP $\left(0.1 \mathrm{nmol} \mathrm{ml}^{-1}, 2.2 \mu \mathrm{Ci} \mathrm{ml}^{-1}\right)$ or with tritiated $N$-acetylglucosamine $\left(0.09 \mathrm{nmol} \mathrm{ml}^{-1}, 2.0 \mu \mathrm{Ci} \mathrm{ml}^{-1}\right)$. The labelled bacteria were filtered using a pre-warmed Millipore filter $(47 \mathrm{~mm}, 0.22 \mu \mathrm{m})$, washed with 3 vols of prewarmed medium, and resuspended in fresh medium. At intervals, samples of labelled cells were removed to boiling SDS (final concentration $4 \%, w / v$ ) and treated as described below. For long-term labelling experiments, bacteria were radiolabelled for two generations with tritiated DAP $\left(2.6 \mathrm{nmol} \mathrm{m}^{-1}, 0.2 \mu \mathrm{Ci} \mathrm{ml}^{-1}\right)$, harvested by centrifugation $\left(2^{\circ} \mathrm{C}, 13000 \mathrm{~g}, 10 \mathrm{~min}\right)$, resuspended in boiling water, and placed in boiling SDS (final concentration $4 \%, \mathrm{w} / \mathrm{v}$ ).

Preparation of labelled peptidoglycan fragments for HPLC analysis. Bacterial samples were boiled in SDS for $15 \mathrm{~min}$ and unlabelled carrier cells were added to samples to aid in the purification procedure. The peptidoglycan was isolated by centrifugation $\left(30000 \mathrm{~g}, 25^{\circ} \mathrm{C}\right)$ and SDS was removed by washing the peptidoglycan five times with hot water $\left(90^{\circ} \mathrm{C}\right)$. The cell-wall fraction was treated with Pronase to remove any contaminating protein (Glauner \& Schwarz, 1988). Peptidoglycan was digested overnight with cellosyl (a muramidase obtained from Dr J.-V. Höltje, Tubingen, Germany) in sodium phosphate buffer $(30 \mathrm{~mm}$, $\mathrm{pH} 4.8$ ). The samples were then heated to $100^{\circ} \mathrm{C}$ for $3 \mathrm{~min}$ and centrifuged to remove any undigested material. Over $95 \%$ of the radiolabel was routinely solubilized by the enzyme. The resulting 
peptidoglycan digests were then dried by rotary evaporation and reduced with sodium borohydride (Glauner et al., 1988).

HPLC analysis of peptidoglycan. The method described by Glauner et al. (1988) was used with the following modifications. A low-pressure gradient preparation system with one pump was used (Waters associates, model 610) rather than a two-pump system. Some separations were performed at $25^{\circ} \mathrm{C}$ as opposed to $55^{\circ} \mathrm{C}$, as the lower temperature improved the separation of the tetra-tetra-tetra muropeptide from the tetra-tri-Lys-Arg muropeptide. Radioactivity was measured with a Radiomatic flow scintillation counter (Packard). The output from this counter was integrated using Maxima software (Waters).

Analysis of HPLC data. All peaks over a minimum set size were integrated by computer. Baselines for all peaks were then adjusted manually. The percentage of cross-linking was calculated as previously described (Martin \& Gmeiner, 1979; Glauner, 1988), except for the cell cycle analysis in which only the peak areas of significant peaks - tri, tetra, tetra-tetra, tetra-tri and tetra-tetra-tetra - were used.

\section{Results}

Composition of Salmonella typhimurium 2616 peptidoglycan

The composition of peptidoglycan from $S$. typhimurium 2616 was determined by HPLC analysis of peptidoglycan radiolabelled with either $\left[{ }^{3} \mathrm{H}\right] \mathrm{DAP}$ or $N$-acetyl $\left[{ }^{3} \mathrm{H}\right]$ glucosamine. The peptidoglycan compositions for bacteria grown with glucose, glycerol or succinate as the principal carbon and energy source are shown in Table 1. Peaks were identified by co-elution with muropeptides prepared from $E$. coli W7 (dap lys; Glauner, 1988). Fig. 1 shows the

Table 1. Peptidoglycan composition for cells grown with glucose, glycerol and succinate as carbon sources

Cultures were labelled with $\left.{ }^{3} \mathrm{H}\right] \mathrm{DAP}\left(2.6 \mathrm{nmol} \mathrm{ml}^{-1}, 0.2 \mu \mathrm{Ci} \mathrm{ml}^{-1}\right)$ for two generations. Peptidoglycan was prepared as described in Methods, and the muropeptides were separated by reverse-phase HPLC. Radioactivity was determined with on-line flow-scintillation counting. The results are the average of determinations on three different cultures for each carbon source. The abbreviations used are as described in the legend to Fig. 1, with the addition of tetra-tetra-Anh 1 and 2, which contain 1,6-anhydromuramic acid, indicating a muropeptide at a chain end.

\begin{tabular}{|c|c|c|c|}
\hline & Glucose & Glycerol & Succinate \\
\hline tri & 7.9 & $6 \cdot 6$ & $7 \cdot 2$ \\
\hline tetra & $36 \cdot 0$ & $31 \cdot 7$ & 28.9 \\
\hline tri-Lys-Arg & $3 \cdot 1$ & $3 \cdot 2$ & $3 \cdot 2$ \\
\hline tri-tri- $\mathrm{A}_{2} \mathrm{pm}$ & 0.4 & $0 \cdot 3$ & $0 \cdot 4$ \\
\hline tetra-tri- $\mathrm{A}_{2} \mathrm{pm}$ & $3 \cdot 0$ & $2 \cdot 9$ & $3 \cdot 3$ \\
\hline tetra-tri & 3.0 & $3 \cdot 2$ & $3 \cdot 8$ \\
\hline tetra-tetra & 29.8 & $30 \cdot 5$ & $27 \cdot 7$ \\
\hline tetra-tetra-tri & 0.5 & 0.8 & 0.9 \\
\hline tetra-tri-Lys-Arg & $2 \cdot 4$ & $2 \cdot 9$ & $4 \cdot 7$ \\
\hline tetra-tetra-tetra & 3.6 & $4 \cdot 6$ & $4 \cdot 6$ \\
\hline tetra-tetra-Anh 1 and 2 & $2 \cdot 0$ & $2 \cdot 2$ & $2 \cdot 2$ \\
\hline Minor components & $8 \cdot 3$ & $11 \cdot 1$ & $13 \cdot 1$ \\
\hline Doubling time (min) & 52 & 67 & 94 \\
\hline Cross-linking & $24 \cdot 29$ & $26 \cdot 11$ & $27 \cdot 22$ \\
\hline
\end{tabular}
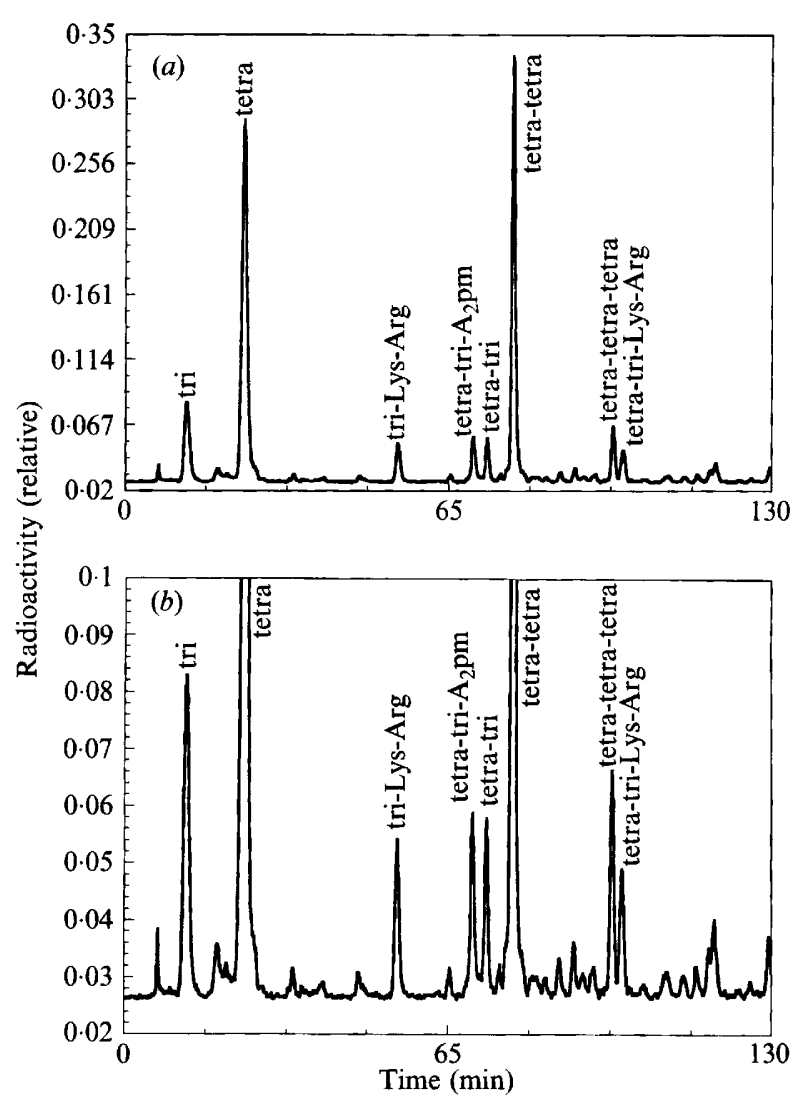

Fig. 1. HPLC profile of radiolabelled muropeptides from an exponential culture of $S$. typhimurium 2616 in glucose-minimal medium. Bacteria were radiolabelled with $\left[{ }^{3} \mathrm{H}\right] \mathrm{DAP}$ and muropeptides prepared as described in the text. The abbreviations used follow the nomenclature used by Glauner (1988): tri, tetra, penta are $N$-acetylglucosamine and $\mathrm{N}$-acetylmuramyl tri-, tetra- and penta-peptides. The tripeptide consists of L-alanine, D-glutamic acid and meso-diaminopimelic acid. The tetrapeptide consists of L-alanine, D-glutamic acid, meso-diaminopimelic acid and D-alanine. The pentapeptide has an additional D-alanine unit. The Lys-Arg residues result from Pronase cleavage of muropeptides from lipoprotein, leaving a lysine and an arginine unit linked to the DAP of a tripeptide. Other muropeptides described are cross-linked combinations of the above monomer units. DAP-DAP cross-linkages are denoted by $\mathrm{A}_{2} \mathrm{pm}$. The data are presented at two different scales to accurately present the major and the minor components.

HPLC elution profile of reduced muropeptides prepared from bacteria grown on glucose and radiolabelled for two generations with $\left[{ }^{3} \mathrm{H}\right] \mathrm{DAP}$. The overall muropeptide composition was similar to $E$. coli; the predominant peaks are the tetra monomer muropeptide and the tetratetra dimer muropeptide. The minor muropeptide components include the tetra-tetra-tetra, tri, tetra-tri and the lipoprotein-associated muropeptides. Bacteria grown with glucose, glycerol, succinate and acetate as carbon sources exhibited similar muropeptide profiles. The only change observed was that the degree of cross-linking showed a consistent decrease with increasing growth rate (Table 1). Bacteria grown on Penassay broth (doubling 


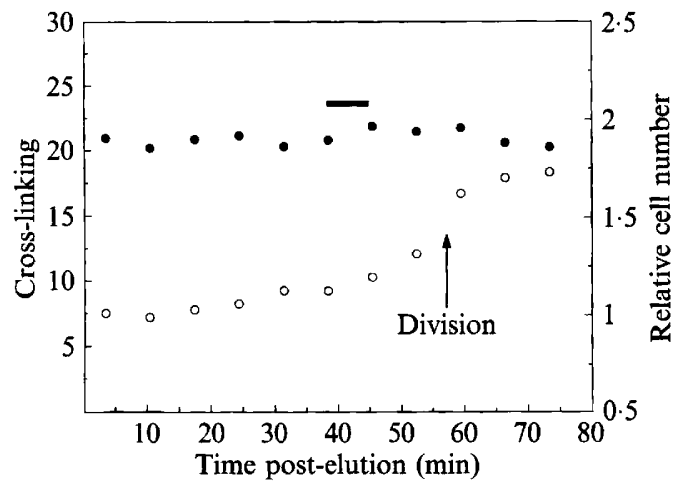

Fig. 2

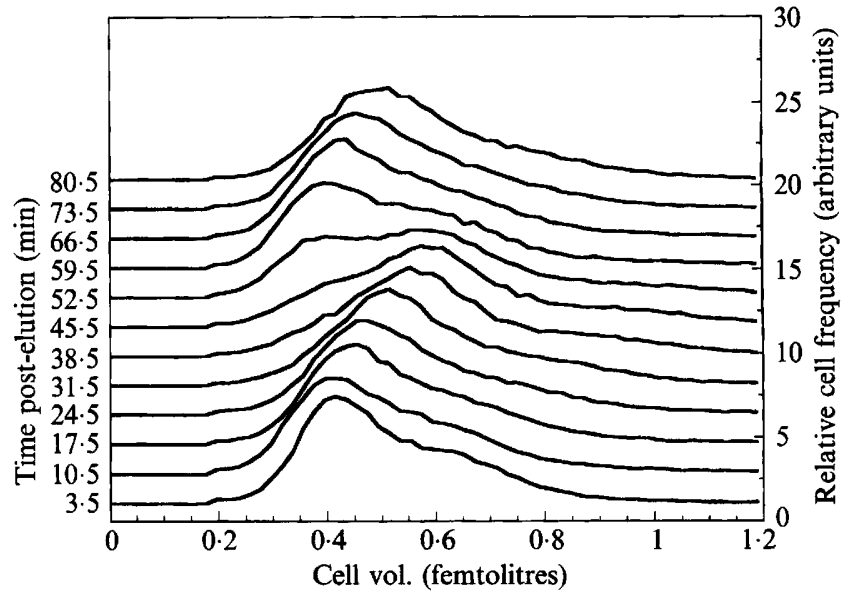

Fig. 3

Fig. 2. Cross-linking during the division cycle. Cross-linking $(\bullet)$ was determined using the peak areas from the tri, tetra, tetra-tri, tetratetra and tetra-tetra-tetra peaks. The increase in relative cell number during the division cycle is also shown $(O)$. The data indicate that the degree of cross-linking remained constant $(21.0 \% \pm 0.5 \%)$. Bacteria from an exponential culture radiolabelled at the same time gave an average cross-linking of $21.9 \% \pm 0.4 \%$. Samples of bacteria were collected off the membrane at 7 min intervals for over one generation, then labelled for $7 \mathrm{~min}$ with $\left[{ }^{3} \mathrm{H}\right] \mathrm{DAP}$. The cell number in each sample was determined at the time of collection and at the time of labelling. The relative cell number increase is the ratio of the final cell number of each sample divided by the initial cell number. Muropeptides were prepared from each sample as described and separated by reverse-phase HPLC. The horizontal bar in the figure indicates the approximate time for maximal DAP incorporation into peptidoglycan relative to leucine. If the increased incorporation of DAP to leucine that occurs during the division cycle is due to pole formation, then the time period indicated by the bar represents the time when division-related changes would be observable. This time precedes the time of most active cell division. The results shown are from a single membrane elution experiment.

Fig. 3. Cell size distribution during the division cycle. The size distributions, for the cells labelled in the experiment presented in Fig. 2, were obtained using a Coulter counter Channelyzer. The results are displayed for each of the fractions analysed for peptidoglycan composition during the division cycle.

time $23 \mathrm{~min}$ ) had peptidoglycan that was $22 \%$ crosslinked. Peaks were found under all growth conditions that co-eluted with the DAP-DAP cross-linked components present in E. coli (Glauner \& Schwarz, 1983), confirming the existence of such cross-links in $S$. typhimurium.

HPLC analysis of glycine-labelled cells showed that no glycine was present in peptidoglycan (data not shown) as reported for E. coli (Glauner \& Schwarz, 1983). The absence of glycine-containing peptidoglycan is probably due to the fact that minimal medium (with lysine as the only added amino acid) was used for this analysis. However, such peaks also appeared to be absent from cells grown on Penassay broth.

Although DAP is an efficient and specific label for peptidoglycan in S. typhimurium 2616 (Cooper et al., 1992), obviously disaccharides without DAP are not detected in the radioactive effluent with this label. However, radiolabelling with $N$-acetyl[ $\left.{ }^{3} \mathrm{H}\right]$ glucosamine demonstrated that disaccharide dipeptide is the only significant component not labelled by DAP. Disaccharides with only one or no appended amino acids were not detected. If the $N$-acetylmuramyl-L-alanine amidase is a primary cell wall hydrolysing enzyme, then this finding is consistent with the enzyme acting only on released muropeptides and not on whole sacculi (van Heijenoort \& van Heijenoort, 1971; van Heijenoort et al. 1975).

\section{Composition of peptidoglycan synthesized at different times during the division cycle}

The composition of newly synthesized peptidoglycan was determined by labelling cells at different points in the division cycle. This was accomplished by collecting newborn cells into pre-warmed culture tubes. After 77 min of collection, a series of 11 tubes was obtained, each with cells of different ages. The last tube contained all newborn cells, and the first tube contained cells that had undergone one division. In order to assess the quality of synchronization, the cell number increase as well as the final cell size distribution were determined. In Fig. 2, the cell number curve shows a delay until cell number starts to increase. An arrow in Fig. 2 indicates the midpoint of the rise in cell number. In Fig. 3, the size distributions demonstrate that the initial newborn small cells increase in size until division occurs; at this time a bimodal distribution is obtained (52.5 min in Fig. 3). At later times, the mean cell size shifts to that of smaller newborn cells, demonstrating that the majority of the cell 


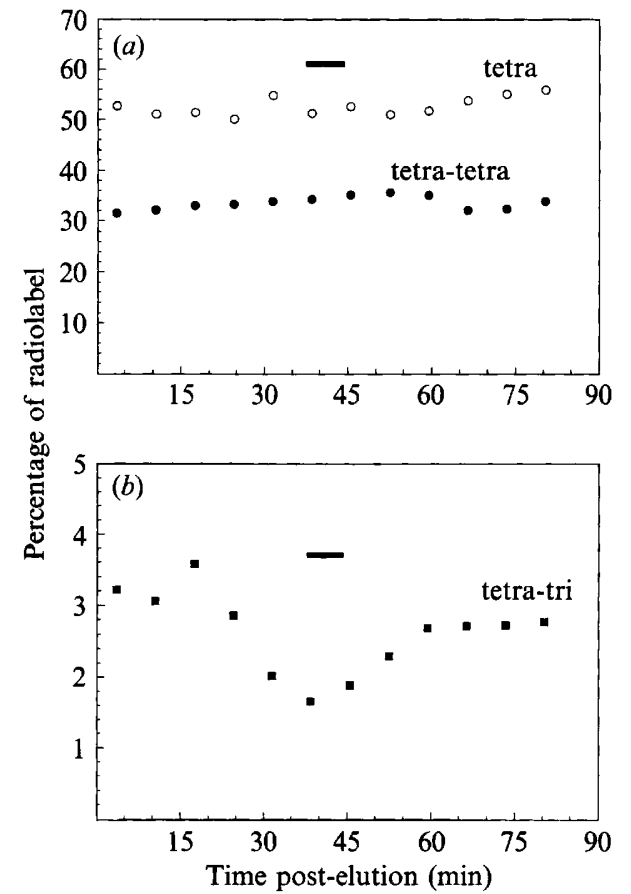

Fig. 4. Percentage of radiolabel in the muropeptides tetra $(O)$ and tetra-tetra ( $)$ during the division cycle. (a) Synchronized samples were labelled for $7 \mathrm{~min}$ with $\left[{ }^{3} \mathrm{H}\right] \mathrm{DAP}$ and muropeptides analysed as described. Control experiments with bacteria taken from exponential culture gave average values of $50.4 \%( \pm 2 \%)$ for the tetra muropeptide and $33.0 \%( \pm 1.7 \%)$ for the tetra-tetra muropeptide. The average values over the cell cycle (samples $1-10)$ were $52.2 \%( \pm 2 \%)$ for the tetra muropeptide and $33.7 \%( \pm 2 \%)$ for the tetra-tetra muropeptide. (b) Percentage of radiolabel in the tetra-tri muropeptide ( $\boldsymbol{\square}$ ) over the division cycle. The average composition over the cell cycle was $2.6 \%$ $( \pm 0.5 \%)$. The composition determined from exponential culture was $3.3 \%( \pm 0.3 \%)$. The bars in both digures indicate the proposed time of maximal DAP incorporation into polar peptidoglycan.

population has completed cell division. The size distribution of the newborn cells is broad; however, we find the presence of a reproducible secondary peak of larger bacteria when the size distribution of newborn cells is analysed. This secondary peak exists as a shoulder on the graph at $3.5 \mathrm{~min}$ in Fig. 3 (size 6.25 femtolitres). A similar result has been shown by Helmstetter et al. (1992) and appears to be due to double nucleoid newborn cells. These bacteria are newly divided and therefore synchronized along with the majority of the eluting cell population. The initial broad size distribution is therefore not an indication that the cells are randomized but rather that newborn cells exhibit a wide size distribution. Such a wide size distribution of newborn cells will result in constriction occurring over a wide time period, as is evident in Fig. 2. However, because multiple time points were taken during this experiment, we feel justified in drawing conclusions from any trends that may be apparent over the course of the division cycle.

The cell samples were labelled with $\left[{ }^{3} \mathrm{H}\right] \mathrm{DAP}$ and

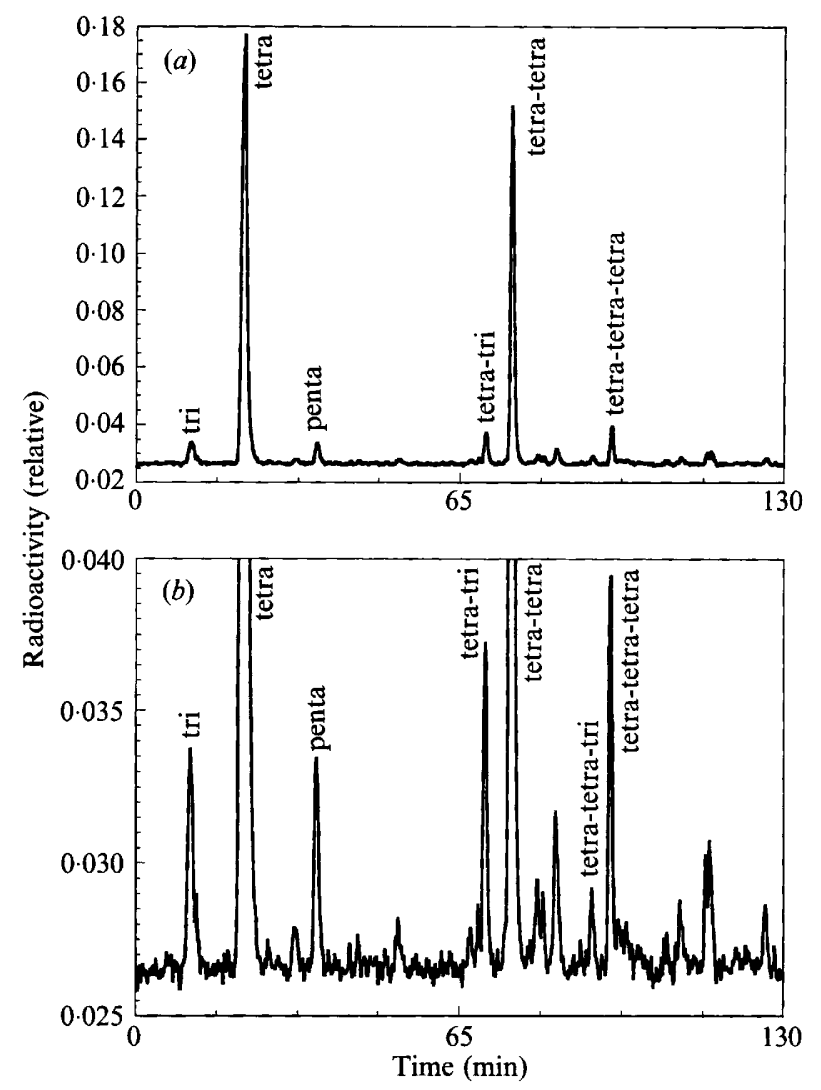

Fig. 5. HPLC profile of reduced muropeptides isolated from synchronized bacteria pulse-labelled for $7 \mathrm{~min}$ with $\left[{ }^{3} \mathrm{H}\right] \mathrm{DAP}$. The profile shown is typical of the radiolabel distribution obtained when examining the composition of peptidoglycan synthesized during the division cycle. Muropeptides were prepared as described in the text. The abbreviations used for the muropeptides are as described in the legend to Fig. 1.

peptidoglycan was prepared for HPLC analysis as described in Methods. An unsynchronized culture was diluted to a similar cell concentration $\left(1 \times 10^{7}\right)$ and four samples were interspersed amongst the synchronized samples as controls. A typical HPLC profile from the labelled synchronized population is shown in Fig. 5. This figure illustrates the predominant peaks that are present after a $7 \mathrm{~min}$ labelling period, and the degree of background against which the radiolabel in each muropeptide peak was determined.

In a separate experiment, a proportion of the synchronized cells was labelled with DAP and leucine. We observed an increase in the ratio of DAP to leucine in the older cells, peaking at 0.7 during the cell cycle. This is in agreement with results obtained using the backwards membrane-elution method (Cooper, 1988; Cooper \& Hsieh, 1988; unpublished results). The bars in Fig. 2 and Fig. $4(a, b)$ indicate the time when the DAP to leucine ratio is maximal. This may indicate the time when septum synthesis, as a fraction of total cell wall, is maximal (Cooper, 1988). 

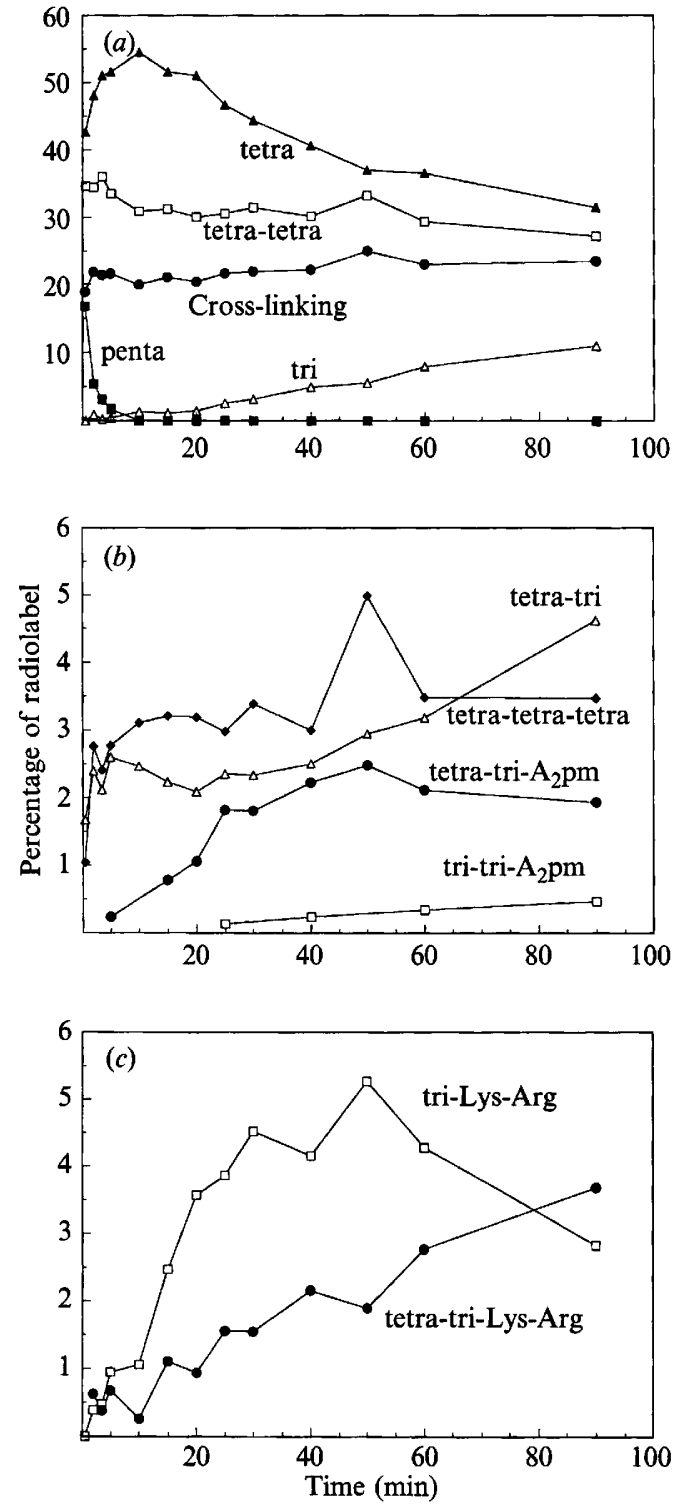

Fig. 6. Maturation kinetics of the muropeptide components of peptidoglycan in S. typhimurium 2616. (a) Major components and cross-linking. (b) Maturation kinetics of some of the less abundant muropeptides of peptidoglycan, including the direct DAP-DAP crossbridges. (c) Maturation kinetics of the main lipoprotein-bound muropeptides. The abbreviations used are described in Fig. 1. The percentage of cross-linking was determined by the method of Martin \& Gmeiner (1979).

The percentage of radiolabelled DAP in tetra, tetratetra and tetra-tri muropeptides during the division cycle are shown in Fig. 4(a,b). The tetrapeptide showed no detectable variation during the division cycle. The tetratetrapeptide exhibited an increase from $31 \%$ to $35 \%$, which was partly offset by a decrease in the radiolabel present in the tetra-tri peak (from $3.2 \%$ to $1.5 \%$ ). The lowest level of label in tetra-tri occurred at the time predicted to be optimal for septal formation (42 min, Fig. $4 b$; see discussion below for an analysis of this result). There was also no detectable systematic variation in the proportion of tripeptide monomer during the division cycle. The degree of cross-linking during the division cycle is shown in Fig. 2. The data indicate that the degree of cross-linking remained constant $(21.0 \%$ $\pm 0.5 \%$ ). Bacteria from an exponential culture radiolabelled at the same time gave an average cross-linking of $21.9 \% \pm 0.4 \%$.

\section{Maturation of peptidoglycan in S. typhimurium}

The peptidoglycan maturation kinetics for $S$. typhimurium 2616 are shown in Fig. $6(a, b, c)$. As expected, the results are in good agreement with the maturation kinetics described for E. coli (Glauner \& Höltje, 1990). An exception was the overall degree of cross-linking which, in contrast to $E$. coli, did not decrease at extended times (Fig. $6 a$ ). Radiolabelling with $N$-acetylglucosamine revealed similar maturation kinetics. Dipeptide monomer demonstrated maturation kinetics similar to the tripeptide monomer (Fig. 6a), increasing from $2 \%$ at $3 \mathrm{~min}$ to $10 \%$ over $90 \mathrm{~min}$. The changes observed with time in the distribution of radiolabelled DAP in the different muropeptides are consistent with a model of peptidoglycan assembly that is described in the Discussion.

\section{Discussion}

The work presented here attempts to answer two questions. First, what is the composition and the maturation kinetics of peptidoglycan in S. typhimurium 2616? Second, does peptidoglycan composition vary during the division cycle?

In agreement with a previous study of peptidoglycan synthesized in a synchronized population of $E$. coli (De Jonge et al., 1989), we present evidence that there is no significant change in the degree of cross-linking of peptidoglycan synthesized during the division cycle. In contrast, the proportions of certain muropeptides did exhibit detectable changes. The proportion of radiolabel in the tetra-tetra dimer muropeptide appeared to increase with constriction, whilst the radiolabel present in the tetra-tri dimer muropeptide decreased. This finding is also consistent with the work of De Jonge et al. (1989). The size distribution of newborn cells was varied and the proportion of the division cycle over which cells were dividing was significant (Figs 2 and 3). In contrast, the synchrony curves produced by utilizing a size-specific fraction of the exponential population, i.e. collected by centrifugal elutriation (De Jonge et al., 1989), are well defined, but we show here that the cell cycle data obtained is comparable. Collection of cells via membrane elution provides minimal perturbations and enables multiple time points to be analysed. Interpretation of 
trends throughout the division cycle is therefore made possible.

The percentage of tetra-tri muropeptide was minimal when pole synthesis was maximal. This finding is to be expected if the probability of newly incorporated strands being inserted side-by-side at the site of constriction (i.e. pole formation) is higher than in cells undergoing only cylindrical elongation. This is a prediction of the leading edge model of constriction (Wientjes \& Nanninga, 1989); i.e. there is more cross-linking between newly inserted nascent strands in the septum than in cylindrical elongation. It is also consistent with the observation of an elevated acceptor-donor radioactivity ratio (ADRR) in constricting cells (De Jonge et al., 1989). Tripeptide monomers are elevated in older strands (i.e. they are a product of maturation, Fig. $6 a$ ); therefore, radiolabelled tetra-tri formation (tripeptide monomer acting as the acceptor peptide) should be reduced in the growing septum where nascent strands are predominantly linked to one another. The increased frequency of nascent strand cross-linking brings about the elevated ADRR found in predominately constricting bacteria, as shown by De Jonge et al. (1989).

We found no evidence that a difference in peptidoglycan structure triggers or localizes septum formation. Such a key role has been proposed for the tripeptide monomer muropeptide (Begg et al., 1990). This muropeptide has been shown to be a better acceptor in transpeptidation reactions involving the proposed septation-specific enzyme, PBP3 (Botta \& Park, 1981; Begg et al., 1990).

The composition and maturation of Salmonella peptidoglycan are similar to $E$. coli. We find that both tri- and dipeptide monomer muropeptides increase from undetectable levels at short labelling times to over $10 \%$ of the total peptidoglycan after two generations of maturation. Therefore, these muropeptides must be components of older peptidoglycan. Different kinetics of tetra-tetra and tetra-tri formation have been used to support the 'patches' model of peptidoglycan assembly (Höltje \& Glauner, 1990) and the 'three-for-one' model (Höltje, 1992). We propose that the different kinetics observed by Höltje \& Glauner (1990) imply neither inter- nor intralayer cross-linking, but simply cross-linking between older and newer strands. Multi-stranded incorporation mechanisms (Burman and Park, 1984; Koch, 1990; Höltje, 1992) are not supported by short-term ADRR determinations, which have given values close to zero (Cooper et al., 1988) indicating single-strand incorporation. This is also the case for assembly of the multilayered, Gram-positive cell wall (Gally et al., 1991). Although several multi-stranded incorporation mechanisms have been proposed to account for peptidoglycan turnover, we do not consider single-stranded incor- poration to be incompatible with turnover. Incorporation of single strands into a carded mesh (Koch, 1988) can easily lead to the redundancy of older material, which is subsequently excised.

Peptidoglycan maturation is consistent with the following conceptual framework, although other descriptions are not excluded. Glycopeptide strands are extended via transglycosylation. The nascent strand is cross-linked to neighbouring strands. The principal cross-bridge formed is the tetra-tetra; a small proportion of linkage between incoming pentapeptides and older tripeptides occurs at this time. The transpeptidation reactions, and concomitant carboxypeptidase activity, rapidly reduce the level of pentapeptide side-chains. The pentapeptide decrease is accompanied by an increase in tetrapeptide monomer (Fig. 6a). This initial tetra monomer increase is followed by a gradual decrease coinciding with a gradual tripeptide and dipeptide monomer increase. It is probable that peptidase action on the tetrapeptide results in the formation of the tri- and dipeptides by removing a DAP unit or a dipeptide unit. (We cannot distinguish between sequential amino acid and dipeptide release in one step at this time.) Proposed peptidases in E. coli (Höltje \& Tuomanen, 1991) can account for two of the main turnover products - free DAP and the DAP-D-Ala dipeptide - that are found in E. coli culture supernatants (Goodell \& Schwarz, 1985). The progression of a radiolabelled pulse into peptidoglycan will result in stages of maturation (Gally et al., 1991): for example, there will be two phases of formation of tetra-tri; the initial phase, when newly inserted material cross-links to older unlabelled tripeptide acceptors, and a later phase, when resident labelled tripeptides become acceptors to unlabelled nascent pentapeptide donors. This logical progression of events will lead to the proportional decrease in certain muropeptides due to later phases of formation of other components.

Glauner \& Höltje (1990) proposed that most tripeptide moieties originate from lipoprotein linked muropeptides. Our results show that both tri and tri-lys-arg muropeptides increase at the same time (Fig. $6 a, c$ ), making it more probable that the majority of tripeptide moieties originate by peptidase action on tetrapeptides. In agreement with Glauner \& Höltje (1990), we find a low initial quantity of lipoprotein-linked muropeptides (Fig. $6 c$ ), followed by a steady increase to $5 \%$ of the total label, followed by a slight decrease, demonstrating that murein synthesis and lipoprotein attachment are separated in time. We also find that the direct DAP-DAP linkages reported by Glauner \& Schwarz (1983) are not present in nascent murein, but increase slowly with time. These linkages are therefore formed by a later, secondary, cross-linking event.

We conclude that the maturation kinetics and the 
mechanism of peptidoglycan synthesis during the division cycle are consistent with previous results obtained with $E$. coli. We propose that the only difference between side-wall and pole synthesis is the increased frequency with which single nascent strands are cross-linked to one another at the site of pole synthesis.

The preparation of this article and the experiments within were supported by National Institutes of Health Grant R01 GM4402201A1. Sandi Cooper's editing made this a better paper than it might otherwise have been. S.C. acknowledges the hospitality of Jochen Höltje and Uli Schwarz during a long term visit to their laboratory in Tubingen. During that visit the enormous potential of the HPLC analysis of peptidoglycan was presented.

\section{References}

Begg, K. J., Takasuga, A., Edwards, D. H., Dewar, S. J., Spratt, B. G., Adachi, H., Ohta, T., Matsuzawa, H. \& Donachie, W. D. (1990). The balance between different peptidoglycan precursors determines whether Escherichia coli cells will elongate or divide. Journal of Bacteriology 172, 6697-6703.

BotTA, G. A. \& PARK, J. T. (1981). Evidence for involvement of penicillin-binding protein 3 in murein synthesis during septation but not during cell elongation. Journal of Bacteriology 145, 333-340.

BURMAN, L. G. \& PARK, J. T. (1984). Molecular model for elongation of the murein sacculus of Escherichia coli. Proceedings of the National Academy of Sciences of the United States of America 81, 1844-1848.

COOPER, S. (1988). Rate and topography of cell wall synthesis during the division cycle of Salmonella typhimurium. Journal of Bacteriology 170, 422-430.

COOPER, S. (1990). Relationship between the acceptor/donor radioactivity ratio and cross-linking in bacterial peptidoglycan: application to surface synthesis during the division cycle. Journal of Bacteriology 172, 5506-5510.

COOPER, S. (1991a). Bacterial Growth and Division: Biochemistry and Regulation of the Division Cycle of Prokaryotes and Eukaryote. San Diego: Academic Press.

COOPER, S. (1991b). Synthesis of the cell surface during the division cycle of rod-shaped, Gram-negative bacteria. Microbiological Reviews 55, 1649-1674.

COOPER, S. \& HSIEH, M.-L. (1988). The rate and topography of cell wall synthesis during the division cycle of Escherichia coli using $\mathrm{N}$ acetylglucosamine as a peptidoglycan label. Journal of General Microbiology 134, 1717-1721.

COOPER, S., HsieH, M.-L. \& Guenther, B. (1988). Mode of peptidoglycan synthesis in Salmonella typhimurium. Journal of Bacteriology 170, 3509-3512.

COOPER, S. \& MetZger, N. (1986). Efficient and quantitative incorporation of diaminopimelic acid into the peptidoglycan of Salmonella typhimurium. FEMS Microbiology Letters 36, 191-194.

Cooper, S., Gally, D., Suneoka, Y., Penwell, M., Caldwell, K. \& BRAY, K. (1992). Peptidoglycan synthesis in Salmonella typhimurium. In Bacterial Growth and Lysis: Metabolism and Structure of the Bacterial Sacculus, pp. 161-168. Edited by M. De Pedro, J.-V. Höltje \& W. Löffelhardt. New York: Plenum.

De Jonge, B. L., WientJes, F. B., JuRIDA, I., Driehuis, F., Wouters, J. T. M. \& NANNINGA, N. (1989). Peptidoglycan synthesis during the cell cycle of Escherichia coli: composition and mode of insertion. Journal of Bacteriology 171, 5783-5794.

DePedro, M. A. \& SCHWARZ, U. (1981). Heterogeneity of newly inserted and preexisting murein in the sacculus of Escherichia coli. Proceedings of the National Academy of Sciences of the United States of America 78, 5856-5860.
Driehuis, F., DeJonge, B. L. M. \& Nanninga, N. (1992). Crosslinkage and cross-linking of peptidoglycan in Escherichia coli: definition, determination, and implications. Journal of Bacteriology 174, 2028-2031.

Gally, D. L., Hancock, I. C., Harwood, C. R. \& ArChibald, A. R. (1991). Cell wall assembly in Bacillus megaterium: incorporation of new peptidoglycan by a monomer addition process. Journal of Bacteriology 173, 2548-2555.

Gally, D. L., Bray, K. \& Cooper, S. (1993). Synthesis of peptidoglycan and membrane during the division cycle of rod-shaped, Gram-negative bacteria. Journal of Bacteriology 175, 3121-3130.

GLAUNER, B. (1988). Separation and quantification of muropeptides with high-performance liquid chromatography. Analytical Biochemistry 172, 451-464.

GlaUNER, B. \& HöltJe, J.-V. (1990). Growth pattern of the murein sacculus of Escherichia coli. Journal of Biological Chemistry 265, 18988-18996.

GLAUNER, B. \& SCHWARz, U. (1983). The analysis of murein composition with high pressure liquid chromatography. In The Target of Penicillin, pp. 29-34. Edited by R. Hakenbeck, J.-V. Höltje \& H. Labischinski. Berlin: De Gruyter.

GLAUNER, B. \& SchwaRz, U. (1988). Chemical analysis of envelope polymers. In Bacterial Cell Surface Techniques, pp. 158-174. Edited by I. Hancock \& I. Poxton. Chichester: John Wiley.

Glauner, B., HöltJe, J.-V. \& SChWARZ, U. (1988). The composition of the murein of Escherichia coli. Journal of Biological Chemistry 263, 10088-10095.

GOODELL, E. W. (1985). Recycling of murein by Escherichia coli. Journal of Bacteriology 163, 305-310.

Goodell, E. W. \& SCHWARz, U. (1983). Cleavage and resynthesis of peptide cross bridges in Escherichia coli murein. Journal of Bacteriology 156, 136-140.

GoODELL, E. W. \& SCHWARZ, U. (1985). Release of cell wall peptides into culture medium by exponentially growing Escherichia coli. Journal of Bacteriology 162, 391-397.

van HeIenoort, Y. \& van Heujenoort, J. (1971). Study of $N$ acetylmuramyl-L-alanine amidase activity in Escherichia coli. FEBS letters 15, 137-141.

van Heijenoort, J., Parquet, C., Flouret, B. \& van Heijenoort, Y. (1975). Envelope-bound $N$-acetylmuramyl-L-alanine amidase of Escherichia coli K12. European Journal of Biochemistry 58, 611-619.

Helmstetter, C. E., Eenhuis, C., Theisen, P., Grimwade, J. \& LEONARD, A. C. (1992). Improved bacterial baby machine: application to Escherichia coli K-12. Journal of Bacteriology 174, 3445-3449.

HöltJE, J.-V. (1992). "Three-for-one" - a simple growth mechanism that guarantees a precise copy of the thin, rod-shaped murein sacculus of Escherichia coli. In Bacterial Growth and Lysis: Metabolism and Structure of the Bacterial Sacculus. Edited by M. De Pedro, J.-V. Höltje \& W. Löffelhardt. New York: Plenum.

HöltJe, J.-V. \& GlauNER, B. (1990). Structure and metabolism of the murein sacculus. Research in Microbiology 141, 75-89.

HöltJE, J.-V. \& TuOMANEN, E. I. (1991). The murein hydrolases of Escherichia coli: properties, functions and impact on the course of infections in vivo. Journal of General Microbiology 137, 441-454.

КоCH, A. L. (1988). Biophysics of bacterial walls viewed as stress bearing fabric. Microbiological Reviews 52, 337-353.

KoCH, A. L. (1990). Additional arguments for the key role of "smart" autolysis in the enlargement of the wall of Gram-negative bacteria. Research in Microbiology 141, 529-541.

MARTIN, H. H. \& GMEINER, J. (1979). Modification of peptidoglycan structure by penicillin action in the cell walls of Proteus mirabilis. European Journal of Biochemistry 95, 487-495.

Romeis, T., Kohlrausch, U., Burgdorf, K. \& HöltJe, J.-V. (1991). Murein chemistry of cell division in Escherichia coli. Research in Microbiology 142, 325-332.

WiENTJES, F. B. \& NANNINGA, N. (1989). Rate and topography of peptidoglycan synthesis during cell division in Escherichia coli: concept of a leading edge. Journal of Bacteriology 171, 3412-3419. 